REVISTA CATALANA DE DRET AMBIENTAL Vol. V Núm. 2 (2014): 1 - 26

- Crònica -

\title{
JURISPRUDENCIA CONSTITUCIONAL EN MATERIA DE PROTECCIÓN DEL MEDIO AMBIENTE
}

\author{
JORDI JARIA I MANZANO \\ Profesor Serra Húnter de Derecho Constitucional y Ambiental \\ Universitat Rovira i Virgili
}


Sumario: 1. Conflictos en relación con la delimitación jurídica de los usos del espacio. 1.1. Defensa de los usos tradicionales del espacio forestal a través de la defensa de la autonomía local: el Parque Natural de Laguna Negra. 1.2. La determinación de los usos de un espacio natural protegido autonómico. 1.3. Un final constitucional para el caso Meseta-Ski. 2. Conflictos energéticos: prima fotovoltaica, fracking y generación eléctrica en el mar territorial. 2.1. Medidas contra el déficit tarifario del sector eléctrico y la prima de la producción energética fotovoltaica. 2.2. El fracking: cuestiones competenciales. 2.3. Autorización de instalaciones energéticas en el mar y organización administrativa. 3. Cuestiones competenciales sobre la Ley del Ruido. 4. Nuevamente las subvenciones estatales en materia de medio ambiente.

\section{Conflictos en relación con la delimitación jurídica de los usos del espacio}

Diversos pronunciamientos del Tribunal Constitucional se han referido, durante el período de análisis de esta crónica, a diferentes conflictos en relación con la delimitación jurídica del espacio. La confluencia de intereses sociales divergentes convierte este ámbito en algo particularmente susceptible de generar desacuerdos entre actores políticos distintos. En esta ocasión, me referiré a un conflicto planteado por un municipio y otros dos por el presidente del Gobierno que se refieren a diferentes facetas del conflicto que se produce cuando dos actores políticos distintos mantienen intereses divergentes sobre el territorio.

1.1. Defensa de los usos tradicionales del espacio forestal a través de la defensa de la autonomía local: el Parque Natural de Laguna Negra

El Pleno del Tribunal Constitucional resolvió en la Sentencia 95/2014, de 12 de junio de 2014 (BOE, núm. 162, de 4 de julio de 2014), el conflicto en defensa de la autonomía promovido por el Ayuntamiento de Covaleda (Soria) en relación con la Ley de las Cortes de Castilla y León 1/2010, de 2 de marzo, de declaración del Parque Natural de Laguna Negra y Circos Glaciares de Urbión. El conflicto tiene por objeto la voluntad de la Comunidad Autónoma de elaborar un nuevo plan de ordenación del espacio natural de Urbión, del que tuvo conocimiento la corporación local afectada en 2005. Posteriormente, en el período de información pública de dicho plan, el Ayuntamiento consideró que, por diferentes razones, vulneraba sus competencias, subrayando que no tenía en cuenta los usos forestales y ganaderos del espacio, que afectaban a la actividad económica de los vecinos del municipio. De hecho, se realizó una consulta entre los vecinos, que mayoritariamente rechazaron el plan.

Aprobado mediante la Ley 1/2010, el municipio interpuso un conflicto en defensa de la autonomía local atendiendo a las razones que habían fundado su rechazo previo del 
mencionado plan, conflicto que resuelve la Sentencia citada. El conflicto plantea la dicotomía entre las formas de explotación tradicional del espacio declarado protegido por la Ley 1/2010 y el nuevo régimen jurídico, que incide en la gestión tradicional del monte, de titularidad municipal. Esta afectación a los usos tradicionales, amparados en la propiedad municipal del espacio, sirve de fundamento para argumentar, por parte de la corporación local afectada, la vulneración de la autonomía local protegida por la Constitución. Por su parte, la Junta de Castilla y León, aparte de diferentes objeciones procesales, considera que la inclusión de un monte de utilidad pública en el espacio natural no altera ni suprime su titularidad, únicamente supone que el Ayuntamiento deberá ejercer sus competencias de acuerdo con la Ley 1/2010, la Ley 8/1991, de 10 de mayo, de Espacios Naturales de Castilla y León, y la Ley 3/2009, de 6 de abril, de Montes de Castilla y León.

El Tribunal Constitucional desestima el conflicto al considerar, por una parte, "que el ámbito geográfico del parque y su propia dimensión regional exceden con mucho del interés puramente local, ya que en la relación entre el interés local y el interés supralocal es claramente predominante este último, sin que pudieran realizarse los intereses públicos que la creación del parque tutela a través de la gestión municipal” (FJ 6. $\left.{ }^{\circ}\right), y$, por otra, que "el Ayuntamiento de Covaleda no ha acreditado que su participación institucional en la gestión del parque natural sea 'una intervención inexistente $o$ meramente simbólica' que impida hacer valer los intereses municipales" (FJ 7. ${ }^{\circ}$ ), todo ello de acuerdo con la STC 170/1989, de 19 de octubre, que el Tribunal Constitucional utiliza como canon en este caso.

En relación con los usos tradicionales del espacio, el papel del municipio y la protección del interés local, el Alto Tribunal subraya que la Ley ordena que las medidas de conservación deberán ser establecidas "en armonía con los usos, derechos y aprovechamientos tradicionales" y deberán servir, entre otros fines, para "mejorar la calidad de vida y el bienestar social de la población asentada" (FJ 7. ${ }^{\circ}$ ). En este sentido, concluye que la Ley impugnada, en sí misma, no constituye una infracción de la autonomía local constitucionalmente garantizada, dejando abierta la discusión de la normativa de desarrollo ante la jurisdicción contencioso-administrativa. 


\subsection{La determinación de los usos de un espacio natural protegido autonómico}

La STC 82/2012, de 18 de abril, resolvió el conflicto originado a partir de la limitación, por parte de una ley foral navarra, del uso como polígono de tiro de una parte del Parque Natural de las Bárdenas Reales de Navarra. El conflicto entre la protección del medio ambiente, aducida por una comunidad autónoma, y el uso militar de ciertos espacios del territorio ha vuelto a ser objeto de un pronunciamiento del Tribunal Constitucional en su Sentencia 154/2014, de 25 de septiembre de 2014 (BOE, núm. 261, de 28 de octubre de 2014), relativa al recurso de inconstitucionalidad interpuesto por el presidente del Gobierno en relación con la Ley de Castilla-La Mancha 6/2011, de 10 de marzo, de declaración del Parque Natural del Valle de Alcudia y Sierra Madrona. Sin embargo, la Ley impugnada presentaba, a juicio del Estado, elementos suplementarios de discusión, todos ellos resueltos en la citada Sentencia.

El objeto de la Ley castellano-manchega era establecer el marco normativo para la conservación del espacio declarado parque natural, para lo cual regulaba los usos, los aprovechamientos y las actividades compatibles, autorizables e incompatibles. El Estado consideraba que tal regulación establecía un marco regulatorio vinculante para todas las administraciones, al mismo tiempo que excluía mecanismos de cooperación. El presidente del Gobierno consideraba que tal norma vulneraba diferentes competencias estatales, particularmente en relación con el artículo 149.1.22 CE y, sobre todo, en relación con el apartado cuarto de este, que se refiere a la defensa. Además, el abogado del Estado considera que se habría producido un desplazamiento de la regla básica de la prevalencia de actuaciones sectoriales excepcionales, tanto del Estado como de las comunidades autónomas, en favor de la absoluta prevalencia de la protección ambiental sobre cualquier otro tipo de actuaciones, lo que sería incompatible con lo dispuesto en la Ley 42/2007, de 13 de diciembre, del Patrimonio Natural y de la Biodiversidad.

En cuanto al último de los aspectos conflictivos, el Tribunal Constitucional considera que "la norma autonómica no impide, ni expresa ni implícitamente la aplicación de las excepciones previstas en la legislación básica", de modo que rechaza la inconstitucionalidad de los incisos impugnados por ese motivo (FJ 4. ${ }^{\circ}$ ). Asimismo, el Tribunal rechaza las pretensiones estatales en relación con una presunta vulneración de sus competencias en materia hidráulica, considerando que "el Estado, y en concreto la planificación hidrológica en las cuencas supracomunitarias, que son las afectadas en 
este caso, está vinculada por la regulación de los usos del espacio natural protegido, sin que ello impida que, en aquellos casos en que, dándose las condiciones excepcionales previstas en la legislación básica, y mediando resolución motivada, el Estado quede desvinculado, en el ejercicio de las concretas facultades que comprenden sus competencias, de la regulación de usos incompatibles que contiene la Ley impugnada. En base a ello, debemos descartar la vulneración de la competencia que sobre aguas supracomunitarias atribuye al Estado el art. 149.1.22 CE" (FJ 6. ${ }^{\circ}$ ). En un caso y en el otro, el Tribunal Constitucional considera que la formulación de la Ley permite los usos excepcionales que el Estado reclama, sin que quepa discutir la opción tuitiva en relación con el espacio conflictivo por parte del legislador autonómico.

Sin embargo, y amparándose en lo ya dicho en la STC 82/2012 en relación con las competencias estatales en materia de defensa, el Tribunal Constitucional considera lo siguiente:

En materia de defensa nacional, este Tribunal ha afirmado que el ejercicio por el Estado de su competencia "impide de raíz toda posibilidad de una acción autonómica de signo contrario. Aquí, en efecto, el Gobierno, en el marco de la competencia exclusiva que sobre defensa reconoce al Estado el art. 149.1.4 CE y de las facultades que le otorga la Ley 8/1975, ha decidido destinar a polígono de entrenamiento de la Fuerza Aérea una zona del territorio castellano-manchego carente de tutela singular como espacio natural protegido, y es evidente que tal decisión no podría verse contradicha por la Comunidad Autónoma concernida a través de una declaración a posteriori de esa zona como Parque, pues semejante declaración, que equivaldría a la pretensión de sustraer a la zona en cuestión al destino que le fue señalado en el ejercicio legítimo de una competencia estatal, implicaría el desconocimiento de ésta y la vulneración consiguiente del citado precepto constitucional. Es cierto que la Comunidad Autónoma de Castilla-La Mancha posee, según antes dijimos, la competencia de declarar como Parque las áreas de su territorio que reúnan las características descritas en el art. 13 de la Ley 4/1989, pero también lo es que la referida competencia no puede ejercerse de modo que quede menoscabada o invadida la competencia del Estado para declarar una zona como de interés para la defensa nacional, ya que -reiterando doctrina consolidada de este Tribunal (cfr., v.g., STC 69/1988, de 19 de abril, fundamento jurídico 3) - el Estado no ha de verse privado del ejercicio de sus competencias por la existencia de una competencia autonómica" (STC 82/2012, de 18 de abril, FJ 4). 
Aunque el Abogado del Estado no ha invocado que los terrenos hayan sido declarados zona de interés para la defensa nacional, que era el supuesto analizado en la Sentencia citada, es indiferente a estos efectos el instrumento jurídico utilizado ya que lo determinante es que ya había ejercido efectivamente la competencia cuando la Ley impugnada declaró el parque natural y prohibió el uso relacionado con la competencia del art. 149.1.4 CE. En consecuencia, la prohibición de maniobras y ejercicios militares conlleva su vulneración. Sin perjuicio de lo expuesto, conviene recordar que este Tribunal ha afirmado, también en materia de defensa nacional (STC 82/2012, de 18 de abril, FJ 3), que las situaciones de concurrencia competencial sobre el mismo espacio físico deben resolverse acudiendo a técnicas de colaboración y concertación. De esta forma, la decisión que adopte el Estado sobre las actividades y usos militares que se vayan a realizar sobre el espacio protegido estará obligada a ponderar los intereses públicos concurrentes y, en especial, los intereses ecológicos y medioambientales que haya tenido en cuenta la Comunidad Autónoma al ejercer su legítima competencia sobre espacios naturales protegidos, y así podrán instarlo las Comunidades Autónomas mediante el ejercicio de las acciones que les competen [la cursiva es mía] (FJ 7. $\left.{ }^{\circ}\right)$.

En este sentido, se reitera la doctrina establecida en la STC 82/2012, que ya comenté en su momento ${ }^{1}$.

\subsection{Un final constitucional para el caso Meseta-Ski}

La Sentencia 162/2014, de 7 de octubre de 2014 (BOE, núm. 262, de 29 de octubre de 2014), resolvió el recurso de inconstitucionalidad interpuesto por el presidente del Gobierno en relación con la Ley de las Cortes de Castilla y León 6/2010, de 28 de mayo, de declaración del Proyecto Regional del "Complejo de Ocio y Aventura MesetaSki”, un proyecto que había ido generando una cierta conflictividad en la Comunidad Autónoma y que, al parecer, encontraría su punto final en la citada resolución del Tribunal Constitucional ${ }^{2}$.

El abogado del Estado impugnó la Ley mencionada por contravenir la legislación básica estatal, dictada de acuerdo con el artículo 149.1.23 CE. Recuerda el impugnante que el

\footnotetext{
${ }^{1}$ Vid. JARIA I MANZANO, J., "Jurisprudencia constitucional en materia de protección del medio ambiente”, Revista Catalana de Dret Ambiental, vol. III, núm. 2, 2012 (http://rcda.cedat.cat/), p. 5 y ss.

${ }^{2}$ I. SANZ RUBIALES se había ocupado de diferentes aspectos de este caso en sus crónicas correspondientes al vol. I, núm. 2 (derecho y políticas ambientales), y al vol. II, núm. 2 (jurisprudencia) (http://rcda.cedat.cat/).
} 
artículo único, apartado 32, de la Ley 10/2006, de 28 de abril, por el que se modifica el artículo 50.1 de la Ley 43/2003, de 21 de abril, de Montes, prescribe que las comunidades autónomas deberán garantizar las condiciones de restauración de los terrenos forestales incendiados, y prohíbe el cambio de uso forestal al menos durante treinta años. Seguidamente, para centrar el caso, señala que los terrenos sobre los que se ubica el proyecto fueron objeto de un cambio de uso forestal para la ejecución de una pista de esquí seco por Resolución de 14 de marzo de 2007 del jefe del servicio territorial de Medio Ambiente de Valladolid, cambio que fue invalidado por la Sentencia del Juzgado de lo Contencioso-Administrativo núm. 1 de Valladolid de 14 de diciembre de 2009. Dicha Sentencia se refería a una anterior, la dictada por el Juzgado de lo Contencioso-Administrativo núm. 2 de Valladolid el 22 de febrero de 2008, que ya había considerado que dicho cambio de uso no era posible a tenor del artículo 50 de la Ley de Montes, por lo que anulaba un acuerdo de la Junta de Gobierno Local del Ayuntamiento de Tordesillas de 4 de octubre de 2006.

Pues bien, este cambio de uso se reitera por medio de la Ley impugnada, lo que lleva al abogado del Estado a considerar que se ha producido una vulneración de la legislación básica estatal en la medida en que pretende soslayar las citadas resoluciones judiciales a través de dotar de rango legal el contenido de los acuerdos anulados, de modo que, a juicio del impugnante, se impediría la regeneración de la cubierta vegetal del monte afectado, devastado por un incendio ocurrido en 1999, contraviniendo la legislación estatal. Por ello, suplementariamente, se alega la vulneración de los artículos. 24.1 y 106.1 de la Constitución, por abuso del privilegio jurisdiccional de las normas con fuerza de ley.

Ante tal planteamiento, la Comunidad Autónoma aduce que, en la medida en que la Ley impugnada se dicta en ejercicio de las competencias autonómicas en materia de ordenación del territorio, la Ley 43/2003, de Montes, no puede servir de canon de enjuiciamiento en este proceso. Considera, además, que la Ley 6/2010 no contiene ninguna habilitación que contravenga la prohibición que establece el artículo 50 de la Ley 43/2003 dado que se limitaría a aprobar un instrumento de ordenación del territorio, con sujeción a las determinaciones que la normativa aplicable exige en esta materia.

El Tribunal Constitucional, después de constatar el carácter básico del artículo 50.1 de la Ley de Montes, pasa a analizar su posible violación en este caso. De acuerdo con el Tribunal Constitucional: 
En este supuesto concreto la Comunidad Autónoma ha ejercido su competencia en materia de ordenación del territorio sobre unos terrenos que se vieron afectados por un incendio en 1999. Así, se confirma en la Sentencia del Juzgado de lo Contencioso-Administrativo núm. 1 de Valladolid, de 14 de diciembre de 2009, donde se reafirma la anulación del cambio de uso forestal de los terrenos de la pista de esquí de Tordesillas. En esta Sentencia se destaca la existencia sobre el proyecto litigioso de diversas resoluciones judiciales, entre ellas, la Sentencia del Juzgado de lo Contencioso-Administrativo núm. 2 de Valladolid, de 22 de febrero de 2008, que había estimado anteriormente que dicho cambio de uso no era posible a tenor del art. 50 de la Ley de montes, y había anulado el acuerdo de la Junta de gobierno local del Ayuntamiento de Tordesillas, de 4 de octubre de 2006, por el que se resolvía conceder la autorización de uso excepcional en suelo rústico para la construcción de la pista de esquí seco en la entidad local menor de Villavieja del Cerro, por desconocimiento del art. 50 de la Ley de montes. La Sentencia del Tribunal Superior de Justicia de Castilla y León, de 28 de mayo de 2009, vino a confirmar la de 22 de febrero de 2008, desestimando el recurso de apelación interpuesto contra la misma, relacionando hasta cuatro motivos para apoyar la afirmación de la Sentencia apelada sobre el desconocimiento que el acto impugnado entraña del art. 50 de la Ley de montes.

Es claro, entonces que la Ley 6/2010, objeto del presente recurso de inconstitucionalidad, pretende desarrollar el proyecto regional "Complejo de ocio y aventura Meseta-Ski" sobre unos terrenos sujetos a las prohibiciones de cambio de uso forestal y de realización de actividades incompatibles con la regeneración de la cubierta forestal establecidas por el art. 50.1 de la Ley 43/2003, de 21 de abril, de montes, sin que nos encontremos, en este caso, en alguna de las excepciones previstas en el inciso segundo del art. 50.1 de aquella Ley, lo que determina la consiguiente vulneración de la legislación básica del Estado.

Atendiendo a lo expuesto debemos afirmar la inconstitucionalidad y nulidad de la Ley 6/2010, de 28 de mayo, de declaración del proyecto regional del "Complejo de Ocio y Aventura Meseta-Ski [la cursiva es mía] (FJ 5.º).

Con ello, parece que las diferentes maniobras para llevar a cabo el proyecto en la zona afectada por el incendio producido en 1999 encuentran un punto final, en la medida en que el Tribunal Constitucional sale al paso de la pretensión del legislador autonómico de salvar los impedimentos que fijaban las resoluciones judiciales citadas. 


\section{Conflictos energéticos: prima fotovoltaica, fracking y generación eléctrica en el mar territorial}

Las cuestiones energéticas parecen haber sustituido al debate hidráulico territorial en tiempos recientes. A la espera de lo que suceda con el paquete de política hidráulica del Gobierno español, al que le queda un año de legislatura, el debate energético pone de manifiesto el conflicto entre la sensibilidad territorial y la planificación centralizada que se proyecta en buena parte de la gestión de los recursos naturales en España, en muchas ocasiones enfrentando un modelo basado en grandes operadores a un modelo de pequeños gestores. La cuestión del fracking es, desde luego, la estrella ambiental del período, pero se han desarrollado otros debates que merece la pena considerar.

\subsection{Medidas contra el déficit tarifario del sector eléctrico y la prima de la producción energética fotovoltaica}

La factura eléctrica plantea uno de los grandes debates energéticos en España en este momento, con un aumento de los esfuerzos que empresas y familias deben realizar para llegar a obtener un suministro eléctrico apropiado en un marco regulatorio que no premia el ahorro ni la autoproducción, esto es, dos de los pilares para avanzar hacia una estructura sostenible del mercado energético. En el período analizado en esta crónica se han resuelto dos recursos de inconstitucionalidad presentados por comunidades autónomas en relación con el Real Decreto-Ley 14/2010, de 23 de diciembre, por el que se establecen medidas urgentes para la corrección del déficit tarifario del sector eléctrico. El primero de ellos corresponde a la impugnación realizada por el Consejo de Gobierno de la Región de Murcia en relación con diferentes preceptos del mencionado Decreto-Ley, y ha sido resuelto por la Sentencia 96/2014, de 12 de junio de 2014 (BOE, núm. 162, de 4 de julio de 2014).

La norma impugnada establecía, entre otras medidas, una modificación muy significativa del régimen jurídico de la producción de energía fotovoltaica, particularmente en relación con el régimen retributivo del Real Decreto 661/2007, estableciendo un peaje de acceso a las redes de transporte y distribución para los productores de energía eléctrica, así como vinculando la percepción del régimen económico primado a que tengan reconocido el número de horas equivalentes, que se establecen en función de las zonas climáticas según la radiación media solar en España, 
reguladas en el Real Decreto 314/2006, de 17 de marzo, por el que se aprueba el Código Técnico de la Edificación. Aparte, también se discutían las medidas establecidas en la disposición transitoria segunda y en la disposición final.

La fundamentación del recurso consiste en la negación de los presupuestos habilitantes para la aprobación de un decreto-ley, con la consiguiente vulneración del artículo 86 $\mathrm{CE}$, en la medida en que no se trataría de medidas concretas para hacer frente a una situación de extraordinaria y urgente necesidad, sino de una alteración sustantiva de la estructura del ordenamiento que, además, se difiere en el tiempo. También se discute la constitucionalidad de las normas impugnadas desde la perspectiva del principio de igualdad, considerando la parte recurrente que se produce una infracción de los artículos 14, 138 y 139 CE. Se añaden también en la impugnación consideraciones sobre la inconstitucionalidad del carácter retroactivo de la norma, en la medida en que el régimen económico aplicable a los productores de instalaciones fotovoltaicas existentes antes de la entrada en vigor del Real Decreto-Ley 14/2010 originó en ellos unas expectativas de ingresos económicos que se ven frustradas con la nueva norma. Finalmente, se alega también la violación de la interdicción de la arbitrariedad prevista en el artículo 9.3 CE.

En definitiva, el recurso discute, en esencia, un cambio sustantivo del régimen jurídico de las instalaciones fotovoltaicas que impacta directamente sobre las inversiones realizadas en el sector de acuerdo con el marco jurídico anterior, siendo, además, que la aplicación del nuevo régimen se modula en función de la ubicación de las instalaciones de un modo que el recurrente considera incompatible con el marco constitucional. El abogado del Estado, por su parte, sostiene, como no podía ser de otro modo, la existencia de presupuesto habilitante para el uso del Decreto-Ley, la inexistencia de violación de los artículos 14, 138 y 139 de la Constitución, así como la inoportunidad de las alegaciones en relación con una retroactividad constitucionalmente prohibida, así como con la interdicción de la arbitrariedad. En definitiva, se sostiene la idoneidad constitucional de un cambio de régimen jurídico que tiene un impacto enorme en la implantación de la energía fotovoltaica en España.

En cualquier caso, la norma impugnada, como sucede habitualmente dada la combinación de la volatilidad del derecho administrativo económico y el retraso permanente del Tribunal Constitucional a la hora de dictar sentencia, había sido modificada en el momento del pronunciamiento del Alto Tribunal por la disposición 
final cuadragésimo cuarta, apartado 2, de la Ley 2/2011, de 4 de marzo. Sin embargo, el Tribunal Constitucional decide pronunciarse en este supuesto, atendiendo a que se trata de un decreto-ley y que, de acuerdo con su propia jurisprudencia, "la Constitución únicamente admite la legislación de urgencia bajo condiciones cuya inobservancia constituye una infracción que sólo puede repararse con una declaración de inconstitucionalidad, sin que los efectos derogatorios de la legislación sobrevenida o los convalidantes de la asunción del decreto-ley por el Congreso de los Diputados puedan corregir un defecto que ha de concebirse como necesariamente insubsanable, pues, en otro caso, los límites del art. 86 CE sólo serían operativos en el tiempo que media entre el Decreto-ley y su convalidación o su conversión en ley, esto es, en un tiempo en el que este Tribunal nunca podrá materialmente pronunciarse" (STC 155/2005, de 9 de junio, FJ 2. ${ }^{\circ}$.

Esto condiciona el pronunciamiento del Tribunal, que se limita a pronunciarse en relación con la existencia o no de supuesto habilitante para la aprobación de un decretoley en el caso concreto. Así, según el Tribunal Constitucional:

La expuesta sucesión de normas nos permite concluir que ninguna de las disposiciones impugnadas se encuentra en vigor en el momento de resolver el presente recurso de inconstitucionalidad, habiendo perdido por consiguiente su objeto en los términos expuestos en el fundamento jurídico anterior debido, como acabamos de exponer, a las reformas normativas producidas por la disposición final cuadragésima cuarta de la Ley 2/2011, de 4 de marzo de economía sostenible, que modificó la disposición final primera del Real Decreto-ley 14/2010, de 23 de diciembre, de modificación del Real Decreto 661/2007, de 25 de mayo; el Real Decreto-ley 9/2013, de 12 de julio, por el que se adoptan medidas urgentes para garantizar la estabilidad financiera del sistema eléctrico, en cuya disposición derogatoria única se derogó el Real Decreto 661/2007, de 25 de mayo, por el que se regula la actividad de producción de energía eléctrica en régimen especial, así como el Real Decreto 1578/2008, de 26 de septiembre, de retribución de la actividad de producción de energía eléctrica mediante tecnología solar fotovoltaica para instalaciones posteriores a la fecha límite de mantenimiento de la retribución del Real Decreto 661/2007, de 25 de mayo, para dicha tecnología; y la Ley 24/2013, de 26 de diciembre, del sector eléctrico, cuya disposición derogatoria única derogó la disposición adicional primera del Real Decreto-ley 14/2010, de 23 de diciembre. 
Con ello, el Tribunal Constitucional entra en una pendiente peligrosa en la medida en que, atendiendo a su lentitud en resolver y la volatilidad de las normativas reguladoras en sectores penetrados por el conocimiento experto y la utilización sistemática de la leymedida, virtualmente elimina el control de constitucionalidad en campos como el sector energético o el sector financiero. En este sentido, aparte de subrayar nuevamente la disfuncionalidad del control de constitucionalidad cuando se produce de forma manifiestamente diferida, cabe criticar la posición del Tribunal en la medida en que crea espacios de oscuridad constitucional en sectores del sistema jurídico, como los mencionados, que son particularmente sensibles en relación con el estatus de los ciudadanos protegidos por la Constitución. Ello llevaría a reclamar una reflexión profunda sobre el control de constitucionalidad en el Estado contemporáneo y su eventual desaparición en los ámbitos más determinantes de la vida de las personas en beneficio de una concepción periclitada y formalista de lo político que acaba siendo impeditiva de un auténtico y efectivo control del poder.

En cuanto al pronunciamiento del Tribunal Constitucional en relación con la eventual inexistencia del presupuesto habilitante para la aprobación del Decreto-Ley impugnado, se parte de una idea sostenida de cierta deferencia hacia el ejecutivo, que se formula en los términos siguientes en el fundamento jurídico sexto de la Sentencia: "La adecuada fiscalización del recurso al decreto-ley requiere, por consiguiente, que la definición por los órganos políticos de una situación 'de extraordinaria y urgente necesidad' sea 'explícita y razonada', del mismo modo que corresponde a este Tribunal constatar la existencia de 'una conexión de sentido o relación de adecuación entre la situación definida que constituye el presupuesto habilitante y las medidas que en el decreto-ley se adoptan, de manera que estas últimas guarden una relación directa o de congruencia con la situación que se trata de afrontar' [...] (STC 237/2012, de 13 de diciembre, FJ 4)". A partir de ahí, el Tribunal Constitucional concluye:

A la vista de los motivos señalados en el fundamento jurídico anterior en lo que respecta a la existencia de presupuesto habilitante, esto es, sobre si concurre la necesaria extraordinaria y urgente necesidad para adoptar las medidas impugnadas mediante real decreto-ley, puede concluirse que la situación de urgencia aparece expresamente justificada en el preámbulo del Real Decreto-ley así como en el debate parlamentario de convalidación del mismo. En ambos casos coinciden las razones que motivaron la adopción de la medida, que son por un lado la situación de crisis económica en 2010, que había repercutido en una caída imprevista de la 
demanda de energía eléctrica, junto al incremento general de costes, que provocó un aumento imprevisto del déficit tarifario. De otro lado la existencia de un régimen retributivo especial, que no se fijó mediante el precio de mercado, sino que tiene como finalidad garantizar una rentabilidad suficiente, que tuvo también una cierta incidencia en déficit tarifario.

Dejando aparte la irrelevancia constitucional, así como el carácter sesgado de la última afirmación, el Tribunal Constitucional valida la utilización de la figura del decreto-ley en la medida en que se justifica por la situación de crisis económica en el momento de adopción de la norma. De este modo, la legislación de urgencia en tiempos de crisis en sectores de alta volatilidad normativa parece poder asumir cualquier contenido, ante un Tribunal Constitucional quizá demasiado tímido a la hora de afrontar la densidad constitucional del derecho administrativo económico. Así, el propio Tribunal considera que no es su competencia "la mayor o menor oportunidad técnica o acierto de las medidas concretas que en el mismo [el Decreto-Ley] se establecen”, así como tampoco “determinar en qué medida el régimen especial primado pueda repercutir sobre el déficit tarifario", de modo que, en definitiva, el conocimiento experto determinaría un espacio normativo casi inmune al control democrático y constitucional.

La Sentencia 109/2014, de 26 de junio de 2014 (BOE, núm. 177, de 22 de julio de 2014), que resuelve el recurso de inconstitucionalidad interpuesto por el Consejo de Gobierno de la Generalitat Valenciana en relación con la disposición transitoria segunda del citado Real Decreto-Ley 14/2010, resuelve en los mismos términos y se remite, en esencia, a lo ya expresado en la comentada STC 96/2014.

\subsection{El fracking: cuestiones competenciales}

La fractura hidráulica, sus consecuencias ambientales y sus posibilidades energéticas han suscitado un debate vivo e interesante en los últimos tiempos. En el marco de este debate, diversas comunidades autónomas han optado por incidir en el régimen jurídico del fracking, en ocasiones impulsando una prohibición absoluta de su utilización en el territorio autonómico. Estas decisiones legislativas han suscitado las reservas del Gobierno central, lo que ha dado lugar a procesos constitucionales que han empezado a resolverse en el período de referencia de esta crónica ${ }^{3}$. La primera de las decisiones del

\footnotetext{
${ }^{3}$ Vid. SANTAMARÍA ARINAS, R. J., "Las claves jurídicas del debate sobre el fracking”, Revista Catalana de Dret Ambiental, vol. V, núm. 1, 2014 (http://rcda.cedat.cat/).
} 
Tribunal Constitucional en esta materia ha sido la Sentencia 106/2014, de 24 de junio de 2014 (BOE, núm. 177, de 22 de julio de 2014), que se pronunciaba en relación con el recurso de inconstitucionalidad interpuesto por el presidente del Gobierno contra la Ley del Parlamento de Cantabria 1/2013, de 15 de abril, por la que se regula la prohibición en el territorio de la Comunidad Autónoma de Cantabria de la técnica de fractura hidráulica como técnica de investigación y extracción de gas no convencional.

El recurso de inconstitucionalidad se dirige contra la Ley del Parlamento de Cantabria 1/2013 en su integridad en la medida en que se considera que la prohibición de la fractura hidráulica, se haga en los términos que se haga, constituye una violación del sistema constitucional de distribución de competencias. Considera el abogado del Estado que se vulneran los títulos competenciales estatales previstos en los artículos 149.1.13 CE (bases y coordinación de la planificación general de la actividad económica) y 149.1.25 CE (bases de régimen minero y energético), de acuerdo con su concreción en el artículo 9.5 de la Ley del Sector de Hidrocarburos, en la redacción de la Ley 17/2013, de 29 de octubre, que constituiría, a su juicio, la norma básica en la materia y que impediría, en particular, a las comunidades autónomas la prohibición de esta modalidad de obtención de energía. Subsidiariamente, considera que tal prohibición es desproporcionada y, en consecuencia, una violación sustantiva de los artículos 128.1 y $130.1 \mathrm{CE}$.

Por su parte, la Comunidad Autónoma - en concreto, la representación procesal de la asamblea legislativa cántabra - sostiene que la Ley viene amparada por la competencia exclusiva que la Comunidad Autónoma de Cantabria tiene en materia de ordenación del territorio y del litoral, urbanismo y vivienda, de conformidad con el artículo 24.3 EACant, así como en materia de protección del medio ambiente y de los ecosistemas (art. 25.7 EACant), sanidad e higiene, promoción, prevención y restauración de la salud (art. 25.3 EACant), industria (art. 24.30 EACant) y régimen minero y energético (art. 25.8 EACant). Lo sustancial, sin embargo, de la argumentación autonómica en este proceso es que la Ley constituye una concreción del mandato constitucional de protección del medio ambiente (art. 45.2 CE) que se presenta como una medida adicional de protección, en los términos del artículo 149.1.23 CE, ya que atribuye una protección superior a la estatal al medio ambiente en esta materia. En este sentido, la representación procesal del Gobierno de Cantabria subraya que el uso del fracking 
comporta riesgos para la salud humana y el medio ambiente por el empleo de aditivos químicos.

El Tribunal Constitucional, sin embargo, renuncia a hacer consideraciones sustantivas y, por lo tanto, nuevamente, a considerar el artículo $45 \mathrm{CE}$ como un precepto constitucional del que quepa extraer consecuencias jurídicas para el legislador. En este sentido, el Alto Tribunal considera, de manera clara, que "las ventajas e inconvenientes de la fractura hidráulica como técnica de exploración y explotación de hidrocarburos no convencionales han dado lugar a un amplio debate no sólo técnico, sino también social, a nivel nacional e internacional, como se refleja en la exposición de motivos de la Ley impugnada". En consecuencia, "[n]o corresponde a este Tribunal tomar postura sobre tema de tan debatido alcance, sino únicamente dictaminar si la Ley impugnada ha incurrido o no en inconstitucionalidad, por extralimitación —alegada por el Gobiernode sus competencias en la materia" (FJ 3. $\left.{ }^{\circ}\right)$.

Centrado el debate en el aspecto puramente competencial, el Tribunal considera que, ante las competencias autonómicas aducidas, "corresponde al Estado la competencia para regular la ordenación del sector energético, y dentro de éste el subsector gasístico, mediante la aprobación de la legislación básica; y a las Comunidades Autónomas corresponden las competencias de desarrollo normativo y ejecutiva, respetando las bases establecidas por el Estado", de acuerdo con la doctrina sentada en las SSTC 135/2012, de 19 de julio (FJ 2. ${ }^{\circ}$ ), y 8/2013, de 17 de enero (FJ 3. ${ }^{\circ}$ ). Dejando aparte las consideraciones sobre el carácter sobrevenido de las bases en este caso, en cualquier caso debe señalarse que el Tribunal Constitucional concluye que la Ley 17/2013, de 29 de octubre, para la garantía del suministro e incremento de la competencia en los sistemas eléctricos insulares y extrapeninsulares, tiene carácter básico y, en la medida en que no prohíbe la fractura hidráulica, la prohibición autonómica deviene inconstitucional (FJ 6. ${ }^{\circ}$ ), ello sin tomar en consideración la posible condición de norma adicional de protección de la prohibición del fracking. En definitiva, el Tribunal considera que la medida autonómica es desproporcionada y, con ello, la inhabilita como norma adicional de protección. Así, afirma en el FJ 8. ${ }^{\circ}$ :

Este Tribunal afirmó en la citada STC 64/1982, de 4 de noviembre, la "necesidad de compaginar en la forma que en cada caso decida el legislador competente la protección de ambos bienes constitucionales: el medio ambiente [art. $45 \mathrm{CE}$ ] y el desarrollo económico [art. 130.1 CE]" (STC 64/1982, FJ 2); asimismo, que el art. 
128.1 CE "supone que no pueden substraerse a la riqueza del país recursos económicos que el Estado considera de interés general, aduciendo otras finalidades como la protección del medio ambiente. Se trata de nuevo de armonizar la protección del medio ambiente con la explotación de los recursos económicos. Ello supone que, si bien la imposición de una carga adicional para la protección del medio ambiente no es en sí contraria a la Constitución ni al Estatuto, sí lo es la prohibición con carácter general de las actividades extractivas $[\ldots]$ de mayor importancia económica [...]. Cuestión distinta es que puedan prohibir la actividad minera en casos concretos, siempre que no exista un interés prioritario, pero el carácter general con la excepción citada, que prevé [...] la Ley impugnada, debe tacharse de inconstitucional [...] por substraer a la riqueza nacional posibles recursos mineros" (STC 64/1982, FJ 6). Esta doctrina se reitera, entre otras, en las SSTC 170/1989, de 19 de octubre, FJ 7, y 102/1995, de 26 de junio, FJ 4.

La prohibición absoluta e incondicionada de una determinada técnica de investigación y explotación de hidrocarburos no puede decidirse por una Comunidad Autónoma. De la doctrina constitucional se infiere sin dificultad que, con la finalidad de protección del medio ambiente, la Comunidad Autónoma puede imponer requisitos y cargas para el otorgamiento de autorizaciones y concesiones no previstos por la legislación estatal, pero sin alterar el ordenamiento básico en materia de régimen minero y energético. La prohibición de la técnica del fracking que establece el art. 1 de la Ley autonómica impugnada vulnera la competencia estatal ex art. 149.1.13 y $25 \mathrm{CE}$, al excluir la eficacia en el territorio de Cantabria de la legislación básica que se dicta al amparo de los referidos títulos competenciales.

A la opinión de la mayoría se adjunta un voto particular que resume buena parte de las objeciones que el autor de estas líneas podría hacer a la argumentación del Tribunal. En particular, dicho voto particular considera lo siguiente:

2. En el encuadramiento material de la presente controversia, de contenido netamente competencial, la Sentencia de la que disentimos adopta un enfoque por completo inusual, cuya generalización produciría muy importantes consecuencias, la más relevante de las cuales consistiría en preterir la competencia autonómica, en éste y prácticamente en cualquier supuesto, al prescindir y dar de lado el juicio de ponderación de títulos competenciales al que en tantas ocasiones este Tribunal se ha sometido. El resultado inducido por tal método sería, en suma, la existencia de un desequilibrio de partida. 
La Ley del Parlamento de Cantabria 1/2013, por la que se prohíbe el fracking en el territorio de esa Comunidad Autónoma, sitúa el conflicto en un marco bien delimitado, siendo una típica manifestación del complejo fenómeno de concurrencia que tiene lugar cuando, en el mismo espacio físico, se proyectan competencias estatales y autonómicas con distinto objeto jurídico. Por ello, el método de análisis debería de haber sido el tradicional en la doctrina constitucional. Conforme viene reconociendo sistemáticamente este Tribunal desde su época más fundacional, el estrecho entrecruzamiento competencial que se produce en este tipo de conflictos hace que la delimitación competencial sea particularmente complicada, pues los títulos competenciales en presencia se limitan y contrapesan recíprocamente, no siendo razonable el propiciar un vacío recíproco de su contenido; o, expresada la idea en otras palabras, los títulos que se invocan han de ejercerse con pleno respeto a las competencias que sobre otras materias pueden corresponder a otra instancia territorial (STC 8/2012, de 18 de enero, FJ 3).

Son varias y complementarias las ideas centrales que conforman esta doctrina, cuyo objetivo último es cohonestar o integrar las distintas competencias. Su más reciente resumen se encuentra en la STC 5/2013, de 17 de enero, FFJJ 6 y 7, de la que aquí interesa destacar: (i) la deseable utilización de técnicas y cauces de cooperación para resolver los conflictos que puedan surgir, (ii) la determinación del título prevalente en función del interés general concernido, que determinará la preferente aplicación de una competencia en detrimento de la otra, y (iii) la necesidad de respetar la esfera de decisión que a cada uno compete, asegurando la debida ponderación de los intereses eventualmente afectados sin preterir unos en beneficio de otros.

Este canon de enjuiciamiento se encuentra ausente en la lógica argumental de la Sentencia, que analiza de forma lineal y por separado los distintos títulos competenciales en presencia, afirmando de entrada (FJ 4) que la controversia se encuadra en el ámbito material de la energía y añadiendo de seguido que, no obstante la incidencia de la protección del medio ambiente en el caso a examen, es aquél, la energía, el título competencial prevalente. Tal premisa, que toma como punto de partida la legislación básica estatal cuya vulneración se aduce, difiere llamativamente de la que puede y debe considerarse la operación canónica de encuadramiento, basada en el análisis del objeto y finalidad de la propia norma controvertida, en el presente conflicto claramente postergado.

Un método semejante abre un punto ciego, pues renuncia a reconocer la concurrencia o entrecruzamiento que se produce en el caso a examen. Y, con ello, 
se aleja del núcleo de la doctrina previa, cuyo Leitmotiv es la integración y la búsqueda de equilibrio entre distintas competencias; un equilibrio que, en definitiva, refleja el que debe perseguirse cuando, más allá de la titularidad de la competencia, son varios los intereses generales o bienes constitucionales en presencia.

3. En la contraposición de la competencia estatal en materia de energía versus la competencia autonómica en materia de protección del medio ambiente, no extendemos nuestra discrepancia al fallo, pues basta remitirse a lo que en un supuesto similar determinó la STC 64/1982, de 4 de noviembre, para apreciar que la prohibición que contiene la ley cántabra, precisamente por su carácter general e incondicionado, no es compatible con el complejo y delicado equilibrio que la jurisprudencia que hemos invocado reclama.

Éste ha sido el criterio constante del Tribunal hasta el presente: en paráfrasis de la ya citada STC 5/2013, FJ 6, el carácter general e incondicionado de esta prohibición implica la prevalencia del criterio autonómico de un modo que ha de reputarse contrario al orden constitucional de distribución de competencias, al no asegurar la debida ponderación de los intereses eventualmente afectados por la concurrencia competencial sobre el mismo espacio físico e imponer la subordinación de unos a otros.

4. Si las anteriores consideraciones hubieran debido entrar en juego al armonizar la protección del medio ambiente con la explotación de los recursos energéticos, con mayor razón hubiera sido necesario fijar un criterio semejante a fin de examinar la finalidad, explícitamente proclamada por la Ley cántabra 1/2013, de proteger la salud humana frente a los riesgos que puede comportar la técnica del fracking.

Tampoco podemos compartir la aproximación metodológica mayoritaria, pues la misma, al debatirse entre subsumir la protección de la salud en la protección del medio ambiente o el débil intento de conferirle una dimensión específica, termina prácticamente soslayando una perspectiva de análisis que, tras esta Sentencia, permanece lamentablemente inédita. Hasta ahora, sólo en la STC 8/2012 se había abordado una cuestión similar (proyectada sobre el binomio telecomunicacionessalud), otorgando un peso determinante a la circunstancia de que, precisamente, la normativa básica del Estado en materia de sanidad haya regulado los niveles de emisión ofreciendo una "solución de equilibrio entre la preservación de la salud y el interés público al que responde la ordenación del sector de las telecomunicaciones" (FJ 6). 
Interesa destacar que en aquella ocasión se alcanzó esta conclusión tras un extenso y reposado análisis del que esta Sentencia carece, que por ello deja abierto un interrogante de muy notable trascendencia: ¿cuál es en este caso la solución de equilibrio, si no existe (o no se invoca) la normativa sanitaria estatal y tampoco se admite que, en ausencia de aquélla, la Comunidad Autónoma pueda ejercer su competencia de desarrollo legislativo en materia de protección de la salud? No cabe ignorar que el derecho a la protección de la salud, que como principio rector reconoce el art. 43.1 CE, “obliga a los poderes públicos 'no sólo al despliegue de la correspondiente acción administrativa prestacional, sino además a desarrollar la acción normativa que resulte necesaria para asegurar el cumplimiento de esos mandatos constitucionales' (STC 113/1989, de 22 de junio, FJ 3). En este sentido, es necesario resaltar que el art. 43.2 CE llama a los poderes públicos a organizar y tutelar la salud pública a través de medidas preventivas y de las prestaciones y servicios necesarios, debiendo ser la ley la que establezca los derechos y deberes de todos al respecto" [STC 137/2013, de 6 de junio, FJ 5 b)].

Aunque estén estrechamente asociados en cuanto a la fuente $\mathrm{u}$ origen del riesgo, la relevancia constitucional de los intereses vinculados a la protección de la salud humana, por un lado, y del medio ambiente, por otro, es sustancialmente diferente. La jurisprudencia constitucional ha resaltado que los intereses generales y públicos vinculados a la promoción y garantía del derecho a la salud están asociados a la defensa de bienes constitucionales particularmente sensibles, conectados en determinados supuestos con el derecho a la integridad física y moral del art. $15 \mathrm{CE}$ (SSTC 35/1996, de 11 de marzo, FJ 3, 207/1996, de 16 de diciembre, FJ 2, 119/2001, de 24 de mayo, FJ 6, 16/2004, de 23 de febrero, FJ 4, 62/2007, de 27 de marzo, FJ 3, 160/2007, de 2 de julio, FJ 2, y 150/2011, de 29 de septiembre, FJ 6).

La Sentencia, en suma, no pondera debidamente la incidencia de los riesgos del fracking en un interés de la máxima relevancia constitucional como es la protección de la salud humana [la cursiva es mía].

Poco más puede añadirse a estas consideraciones más allá de la necesidad de que, de una vez, el Tribunal Constitucional empiece a extraer consecuencias efectivas del artículo $45 \mathrm{CE}$ en el sentido no solo de habilitar, sino también de limitar la acción de los poderes públicos. La Sentencia 134/2014, de 22 de julio de 2014 (BOE, núm. 199, de 16 de agosto de 2014), reproduce los argumentos de la comentada en relación con el recurso de inconstitucionalidad interpuesto por el presidente del Gobierno respecto de la Ley del Parlamento de La Rioja 7/2013, de 21 de junio, por la que se regula la 
prohibición en el territorio de la Comunidad Autónoma de La Rioja de la técnica de la fractura hidráulica como técnica de investigación y extracción de gas no convencional. Los magistrados firmantes del voto particular de la STC 106/2014 (Valdés Dal-Ré, Xiol Ríos y Asua Batarrita) reiteran su discrepancia con la mayoría remitiéndose a su posición anterior.

\subsection{Autorización de instalaciones energéticas en el mar y organización administrativa}

El conflicto positivo de competencias planteado por el Gobierno de Canarias en relación con el Real Decreto 1485/2012, de 29 de octubre, por el que se modifica el Real Decreto 1028/2007, de 20 de julio, por el que se establece el procedimiento administrativo para la tramitación de las solicitudes de autorización de instalaciones de generación eléctrica en el mar territorial, para adaptarlo a la nueva denominación y estructura de los departamentos ministeriales, ha sido resuelto por la Sentencia del Tribunal Constitucional 121/2014, de 17 de julio de 2014 (BOE, núm. 198, de 15 de agosto de 2014). Según el órgano recurrente, la norma discutida no tiene un carácter meramente orgánico en la medida en que declara o ratifica, pero con un pronunciamiento innovador derivado de las circunstancias y del Derecho sobrevenido, que la competencia para resolver los procedimientos relativos a las instalaciones eólicas que se sitúen en el mar territorial corresponde a los órganos de la Administración del Estado que en ella se citan.

Entiende el Gobierno canario que no es de aplicación, en relación con el Decreto 1485/2012, la competencia asumida por las instituciones centrales del Estado de acuerdo con el artículo 149.1.22 CE, ya que, en el caso de la comunidad insular, la simple ubicación de las instalaciones que se autorizan en el mar territorial no es suficiente para colegir que la energía que en ellas se genere va a ser utilizada fuera de la comunidad autónoma respectiva, sino, más bien al contrario, es plausible que se utilice solo en la comunidad autónoma afectada. Según el Gobierno canario, toda la energía que se produce en Canarias se consume en Canarias y no se puede transportar no ya a la Península, sino ni siquiera de una isla a otra. Tampoco serían de aplicación el 149.1.18 ni la atribución al Estado del dominio público hidráulico. Debería estarse, en opinión del recurrente, a lo dispuesto en el Estatuto de Autonomía en materia de energía (artículos 30.26 y 32.9 ). 
Sin embargo, el Tribunal Constitucional niega que pueda hablarse de una vulneración de las competencias autonómicas en este caso, en la medida en que reconduce la norma estatal a lo que su propio título indica, esto es, a las facultades de autoorganización de la Administración del Estado, concluyendo lo siguiente:

\begin{abstract}
A la vista de la regulación controvertida y dando así respuesta a la cuestión planteada por ambas partes acerca de si el Real Decreto 1485/2012 afecta o no a las competencias que la Comunidad Autónoma Canaria reivindica en relación con el procedimiento administrativo para la tramitación de las solicitudes de autorización de instalaciones de generación eléctrica en el mar territorial, no cabe sino afirmar que la misma es una regulación establecida de acuerdo con la potestad de autoorganización que le corresponde al Estado. Incluso podría considerarse que el Real Decreto 1485/2012 más que una norma de organización es una norma que se limita a introducir un mero cambio nominal en el Real Decreto 1028/2007. En efecto, la modificación efectuada por el Real Decreto 1485/2012 se limita a la actualización de la denominación de Departamentos Ministeriales y órganos superiores y directivos a los que hace referencia el Real Decreto 1028/2007, si bien dichas previsiones no producen atribución competencial alguna y ni siquiera reproducen las funciones que el Real Decreto 1028/2007 reconoce a cada uno de los Departamentos Ministeriales y de diferentes órganos de la Administración del Estado.
\end{abstract}

\title{
3. Cuestiones competenciales sobre la Ley del Ruido
}

El 19 de febrero de 2004, el Parlamento de Cataluña interpuso recurso de inconstitucionalidad contra la disposición final primera de la Ley 37/2003, de 17 de noviembre, del Ruido, en la medida en que declaraba aplicables al artículo 4.2 y 3 y a las disposiciones adicionales segunda y tercera los títulos competenciales del artículo 149.1.13, 20, 21 y $24 \mathrm{CE}$, y en la medida en que declaraba básicos los artículos 10.2, 12.1 y 3, 13 a), y 15.3, así como la disposición adicional séptima. Después de diez años, el Tribunal Constitucional se ha pronunciado mediante la Sentencia 161/2014, de 7 de octubre de 2014 (BOE, núm. 262, de 29 de octubre de 2014).

En relación con la primera parte del recurso, el Parlamento de Cataluña consideraba que las disposiciones impugnadas, al no ser de aplicación los títulos competenciales aducidos por el Estado, estaban privadas de cobertura jurídica y, en consecuencia, eran inconstitucionales. Por otro lado, los demás preceptos, en la medida en que no se podían 
calificar de básicos por su carácter habilitador de la acción del ejecutivo central, carecían, asimismo, de cobertura.

El abogado del Estado, por su parte, se refiere a la jurisprudencia sobre la evaluación de impacto ambiental, sentada de la controvertida STC 13/1998, de 22 de enero, que ya he criticado en estas mismas páginas en ocasiones anteriores. Efectivamente, en la medida en que el Tribunal Constitucional extrajo allí, de las competencias ejecutivas en materia de medio ambiente, aquellos instrumentos de tutela ambiental que se proyectaban sobre competencias sectoriales, abrió el camino para impedir a los actores competentes en relación con la ejecución de la normativa de protección del medio ambiente, esto es, las comunidades autónomas, ejercer su acción tuitiva sobre las infraestructuras estatales, siendo la normativa impugnada, a juicio del abogado del Estado, una norma en sintonía con tal doctrina. Por otro lado, en relación con la segunda parte del recurso, la representación procesal del Gobierno central considera que no se ha fundamentado suficientemente el carácter no básico de los preceptos impugnados.

A la hora de enjuiciar los títulos competenciales que la Ley establece en relación con el fundamento de los apartados 2 y 3 de su artículo 4, el Tribunal Constitucional parte de que "[r]esulta evidente, a la vista de lo expuesto, que la legislación dirigida a evitar los efectos nocivos que el ruido ambiental tiene sobre la salud humana responde de manera principal a la materia medioambiental" (FJ 4. ${ }^{\circ}$. Sin embargo, dada la transversalidad de la protección del medio ambiente, el Tribunal considera, en aras de limitar la vis expansiva de las competencias en esta materia, que "las competencias en materia de medio ambiente pueden condicionar el ejercicio de otras actuaciones con incidencia territorial, pero no pueden invadir el ámbito reservado a las competencias en virtud de las cuales se desarrollan" (FJ 4. ${ }^{\circ}$ ). A partir de aquí, y con la idea de impedir que la función tuitiva de las comunidades autónomas respecto a la protección del medio ambiente dificulte de manera relevante el ejercicio de las competencias estatales en relación con las infraestructuras, de acuerdo con la línea jurisprudencial sentada en la mencionada STC 13/1998, el Tribunal concluye lo siguiente:

En el supuesto que nos ocupa, a pesar de que la regulación de la Ley del ruido pudiera entenderse dotada de sustantividad y especificidad propias, la atribución a la Comunidad Autónoma de todas las funciones previstas en la Ley (y, más concretamente, en el art. 4.1) en los supuestos de determinadas infraestructuras y obras de interés público competencia del Estado, tropezaría con un obstáculo 
insalvable. De ser así, se estaría admitiendo que las Comunidades Autónomas pudieran legislar y desarrollar funciones ejecutivas sobre todas ellas, a pesar de las competencias de carácter exclusivo que al Estado reservan sobre aquéllas diversas cláusulas del art. 149.1 CE. Como recuerda la STC 5/2013, de 17 de enero, FJ 4, esta posibilidad se encuentra excluida por nuestra doctrina, ya que implicaría la prevalencia del criterio autonómico en relación con tales infraestructuras, lo que resultaría contrario al orden constitucional de distribución de competencias, al preterir los títulos competenciales a los que, de acuerdo con la Constitución y los Estatutos de Autonomía, se encuentran sometidas aquéllas. En este punto, no se puede ignorar que cuando la Constitución atribuye al Estado una competencia exclusiva lo hace porque bajo la misma subyace un interés general, que debe prevalecer sobre los intereses que puedan tener otras entidades territoriales afectadas, siempre y cuando aquella competencia se ejerza de manera legítima (STC 204/2002, FJ 7. ${ }^{\circ}$ ).

Existiendo mecanismos de información y colaboración, indispensables, a juicio del Tribunal, en supuestos como este de entrecruzamiento de competencias autonómicas y estatales, considera, en definitiva, que no hay violación de las competencias autonómicas. En este caso, sin embargo, lo relevante es que, contrariamente a lo que sucedía en el caso de la evaluación de impacto ambiental, las disposiciones discutidas no desgajan la función legislativa de la función ejecutiva en materia de medio ambiente, sino que atribuyen un título competencial al Estado diferenciado del artículo 149.1.23 CE para permitirle desarrollar la función ejecutiva en determinados ámbitos, integrando la protección ambiental en la competencia sectorial. En este sentido, la opción de la Ley del Ruido, siendo discutible en la medida en que constituye un menoscabo de las competencias ambientales autonómicas, reposa en una estructura lógica de impecable coherencia.

Ello no impide al Tribunal Constitucional continuar expresando el subtexto de la STC 13/1998 cuando afirma que "la competencia del Estado comprende necesariamente la determinación de las limitaciones de usos y servidumbres en terrenos afectados por sus infraestructuras cuando unos y otras están al servicio del funcionamiento y desarrollo de tales infraestructuras; de otro modo las Comunidades Autónomas podrían dificultar o impedir el ejercicio de la competencia estatal sobre las obras públicas de interés general". Ello, sin embargo, no es concluyente, ya que, a la inversa, la ejecución de las competencias estatales en estos términos impide, de hecho, el ejercicio de las 
competencias autonómicas en materia de protección del medio ambiente. En mi opinión, el Tribunal Constitucional debería revisar la jurisprudencia sentada en la mencionada Sentencia y buscar un fundamento más sólido a la hora de cohonestar el ejercicio de las competencias estatales en relación con las infraestructuras de interés general y las competencias autonómicas ejecutivas en materia de protección del medio ambiente.

En cuanto al segundo debate planteado por el recurso, el referido a la condición de básicas de determinadas disposiciones de la Ley del Ruido, el Tribunal Constitucional parte del consabido carácter expansivo de las bases, que ha ido consolidando en su jurisprudencia, siendo especialmente generoso con el papel del Gobierno central en su fijación. Así, el Alto Tribunal fija su punto de partida en los términos siguientes:

Expuestos a grandes rasgos los términos del debate en este punto del recurso de inconstitucionalidad, debemos comenzar su análisis acudiendo a nuestra doctrina sobre los requisitos formales de lo básico. Así, dijimos en la STC 131/1996, de 11 de junio, FJ 2, que "para garantizar la generalidad y estabilidad consustanciales a las reglas básicas (STC 147/1991), éstas deben establecerse mediante ley formal votada en Cortes, aunque, como excepción, quepa admitir que en ciertas circunstancias el Gobierno pueda regular por Real Decreto aspectos básicos de una determinada materia. Estas circunstancias excepcionales se dan, según hemos reiterado, cuando el reglamento resulta 'complemento indispensable' para asegurar el mínimo común denominador establecido en las normas legales básicas (por todas SSTC 25/1983, 32/1983, 48/1988): Es indispensable cuando la ley formal no resulta instrumento idóneo para regular exhaustivamente todos los aspectos básicos, debido al 'carácter marcadamente técnico o a la naturaleza coyuntural y cambiante' de los mismos (SSTC 76/1983, 787/1985, 86/1989, 147/1991, 149/1992, entre otras), y es complemento de las normas legales básicas, cuando, además de ser materialmente básico, actúa como desarrollo de una ley que previamente ha acotado el alcance general de lo básico". Y, en este sentido "el Gobierno puede regular por vía reglamentaria materias básicas definidas como tales en normas de rango de ley, porque entonces su actuación es completiva y no delimitativa o definidora de competencias (SSTC 25/1983, 32/1983, 42/1983, entre otras)”. En esta misma línea ha afirmado este Tribunal que la regulación reglamentaria de materias básicas por parte del Gobierno resultaría acorde con los preceptos constitucionales si, primeramente, cuenta con una habilitación legal, y, en segundo lugar, si su rango reglamentario viniera justificado por tratarse de 
materias cuya naturaleza exigiera un tratamiento para el que las normas legales resultaran inadecuadas por sus mismas características (entre otras, SSTC 184/2012, de 17 de octubre, FJ 3; 214/2013, de 14 de noviembre, FJ 3; 25/2013, de 31 de enero, FJ 4; y 162/2013, de 26 de septiembre, FJ 5). Todo ello sin perjuicio de que, como advertimos en la STC 77/1985, de 27 de junio, FJ 16, “si el Gobierno, al dictar las correspondientes normas reglamentarias en virtud de esa remisión, extendiera su regulación a aspectos no básicos o no cubiertos por la habilitación legal, que pretendiera fueran de aplicación directa en el ámbito de las Comunidades Autónomas que hubieran asumido competencias de desarrollo en esta materia, estas Comunidades Autónomas podrían, de ser así y en cada caso, plantear el oportuno conflicto de competencias ante este Tribunal Constitucional, que debería, en cada supuesto, examinar si se hubiera producido o no el traspaso del ámbito competencial estatal". Ahora bien, la mera remisión en abstracto a las normas reglamentarias para regular materias básicas no tiene por qué suponer necesariamente que esas normas vulnerarían las competencias asumidas por las Comunidades Autónomas, ni puede reputarse sin más inconstitucional [la cursiva es mía] (FJ 7. ${ }^{\circ}$.

A partir de aquí, el Tribunal considera legítima la remisión a la acción del Gobierno en la determinación de los aspectos técnicos cambiantes relativos al despliegue de la Ley, sin discutir si, precisamente, esa condición de aspectos técnicos cambiantes los priva, quizá, de su carácter básico. Seguramente, el desequilibrio en la acción legislativa de las comunidades autónomas conlleva que, finalmente, se termine aceptando una acción expansiva de las instituciones centrales del Estado que termina por mutar la naturaleza básica de sus competencias. Esta es una de las fallas fundamentales del sistema autonómico - pretendidamente homogéneo a juicio de muchos-, cuyo comentario supera con mucho el objeto de estas líneas.

\section{Nuevamente las subvenciones estatales en materia de medio ambiente}

La Sentencia 144/2014, de 22 de septiembre de 2014 (BOE, núm. 261, de 28 de octubre de 2014), resuelve el conflicto positivo de competencia planteado por la Generalitat de Catalunya respecto de la Orden ARM/2876/2008, de 2 de octubre, por la que se establecen las bases reguladoras para la concesión de subvenciones a asociaciones declaradas de utilidad pública y fundaciones adscritas al protectorado del Ministerio para la realización de actividades relativas a programas que se desarrollen en relación 
con la defensa del medio natural y la biodiversidad, la utilización sostenible de los recursos naturales y la prevención de la contaminación y del cambio climático, y respecto de la Orden ARM/3020/2008, de 22 de octubre, que convoca esas ayudas para el ejercicio 2008.

El Tribunal Constitucional, a la hora de analizar la controversia, parte de la asunción de que nos encontramos de lleno en materia de protección del medio ambiente, con lo que su argumentación se concentra en determinar si los preceptos impugnados tienen o no carácter básico, lo que, en su caso, habilitaría al Estado para intervenir. Establecidos los términos del debate, se trata, a juicio del Alto Tribunal, de saber si "si en este caso concurren o no las circunstancias excepcionales que, según el fundamento jurídico $8 \mathrm{~d}$ ) de la STC 13/1992, justifican la regulación completa de las subvenciones y la centralización de su gestión, pues de lo contrario, al ser la materia afectada por aquéllas de competencia compartida, será de aplicación la doctrina constitucional establecida en el fundamento jurídico 8 b) de dicha Sentencia, conforme a la cual corresponde al Estado la regulación básica de la ayudas y a las Comunidades Autónomas el desarrollo de dicha regulación y la entera gestión”. El Tribunal recuerda que consideró un caso virtualmente idéntico en la STC 113/2013, de 9 de mayo ${ }^{4}$. Resuelve, pues, en el mismo sentido que aquella resolución, declarando que las bases tercera, quinta, séptima, octava y decimotercera de la convocatoria vulnerarían las competencias de la Generalitat.

\footnotetext{
${ }^{4}$ Resolución que comenté en "Jurisprudencia constitucional en materia de protección del medio ambiente", Revista Catalana de Dret Ambiental, vol. IV, núm. 2, 2013 (http://rcda.cedat.cat/), p. 9 y ss.
} 